\title{
Improving Clinical Skills of Medical Students Based on the Clinical Skills Competition
}

\author{
Linqiang Jiang, Dan Fang, and Mao Luo
}

\begin{abstract}
This paper starts with medical students' personal experiences of participating in the clinical skills competition to explore the benefits for medical students to carry out the clinical skills competition. Taking the clinical skills competition as the carrier, this paper conducts an all-around investigation on the important role of the clinical skills competition in improving the clinical skill of medical students.
\end{abstract}

Index Terms-Clinical skills, competition, comprehensive quality, practical ability.

\section{INTRODUCTION}

The medicine is the very practical science. And the training of basic clinical skills has always been an important part of clinical medical education. Along with the development of the medical and health services in China as well as the proceeding of deepening the medical system reform, the training of medical students' clinical skills is facing new tasks and requirements [1]. In order to raise wide concerns from all walks of life and great attention from all medical colleges and universities, the Ministry of Education started to organize the national clinical skills competition for students in the medical colleges and universities (hereinafter referred to as the national clinical skills competition) in 2010, aiming at leading the reform orientation of the national clinical medicine education and promoting the clinical skills of medical college students. Meanwhile, based on the competition, we can timely discover the common problems in Chinese training process of students' clinical skills, and reach a consensus step by step with mass discussion. This will be a great promotion to build the operation standard for clinical skills in the medicine education system of China [2].

\section{The Clinical Skills COMPETITION CREATES OpPORTUNities to PRACTICE FOR MEDICAL CREATES}

Since 2003, the School of Clinical Medicine in Luzhou Medical College has held the clinical skills competition every year and has successfully organized nine sessions so far. The senior undergraduates of fourth and fifth year from the clinical medicine science of the whole college can participate in this competition. Students shall pass the preliminary and intermediary contest and then enter the final. There are three stages in the final. The first step is to answer

Manuscript received May 8, 2013; revised July 6, 2013. This work was supported in part by Social science research program of Luzhou Medical College (2010116).

The authors are with Basic Medical School of Luzhou Medical College, Luzhou646000, China (e-mail: luomao20050908@163.com). quick-response questions and required questions which examine the basic medical theory and image inspection knowledge of those teams participating in the contest. The second stage includes the inquiry, physical examination, clinical diagnosis \& treatment and the humanistic care to the patient. The third stage tests students' basic operation of surgery and emergency treatment on the spot. After every stage, experts and professors will make detailed and professional comments to teams and point out their shortcomings and details to be noted. Thus students at present can also benefit a lot from the competition. This approach of "promoting learning with competition" is of great importance in enhancing the professional ability of medical students, further regulating the training assessment work in clinical practice teaching and constantly improving the quality of talent cultivation. The clinical skills competition provides a platform for medical students to demonstrate self-competence and charisma and creates practical opportunities for them. The clinical thinking ability, clinical skills of students and the humanism spirit of medicine can be presented intensively in the competition, creating an atmosphere for constantly promoting medical students' clinical professional level. Besides, the competition can also offer empathic learning for students on the point of clinical practices and provide a platform for them to learn clinical knowledge.

\section{The CliniCAL SKILls COMPETITION BUILDS UP Medical Students' CliniCAL SKILls}

Based on the epistemology, people are always forming abstract recognition through specific things and then using abstract recognition in the guidance of new concrete practices. Therefore, "learning by doing" acts as the most effective way to learn. It means learning relative knowledge and ability by doing specific things. The practicalness is an outstanding feature of medicine and the cultivation of medical students' clinical skills is an important part of medical education [3]. Due to various factors such as the enrolment expansion of colleges, the clinical medical education is facing a throng of problems and challenges. The traditional teaching method of clinical medical education is severely impacted. On one hand, the increase in the number of medical students causes reduction in students' average education cost and internship beds, and on the other hand, problems emerge in the clinical practice due to lacking of protection from relevant policies and laws. The cultivation of medical students is too dependent on lectures and observation to enable students to really get skills relevant to various clinical operations. Thus, the clinical 
practice presents a weakening and downward tendency. Nowadays, with increasingly worsening employment situation of medical students, most of medical units want to recruit talents with qualifications for practicing doctors as well as working experience during recruitment. Their core concerns are actually the clinical professional ability of talents. Though current year's medical graduates, especially the undergraduate students, have mastered basic professional ability, they only restrict themselves to book knowledge. There are many professors in the university, but no "coaches". As a result, medical students need opportunities with dynamic integration of theory and practice. The skills competition provides an effective platform for the cultivation of college students' professional skills to build up their practical ability [4], [5]. As the saying goes, "Practice is the sole criterion for testing truth". Current college students' learning of professional knowledge is purely for taking tests. At the end of the examination, they will thoroughly forget all the theoretical knowledge. What causes this phenomenon? College students only study but not practice, so it' $\mathrm{s}$ inevitable for them to forget the knowledge easily. The professional knowledge can be further consolidated in the process of practice. Hence, the clinical skills competition creates a new way for college students in their learning [6], [7].Over the years, the implementation of clinical skills competition has ensured constant improvement of the teaching quality in our college and the clinical teaching has also been recognized by our counterparts. In nearly four years, the employment rate of clinical medicine colleges is above $95 \%$, and the postgraduate entrance exams passing rate of graduates in 2010 was $21.2 \%$, in 2011 was $27.7 \%$ and in 2012 was $26.5 \%$; in 2009, the passing rate of 1459 graduates participating in the national medical practitioners examination was $57.99 \%, 5.93$ percentage points higher than the national average (the total passing rate of examinees all over China was 57.6\%); in 2010, the passing rate of 1204 graduates taking part in the national medical practitioners examination was $69.19 \%, 11.32$ percentage points higher than the national average (the total passing rate of examinees all over China was $57.87 \%$ ); and in 2011, the passing rate of 926 graduates attending the national medical practitioners examination was $70.93 \%, 13.33$ percentage points higher than the national average (the total passing rate of examinees all over China was 57.6\%).

\section{The CliniCAL SKILls COMPETITION ENHANCES MEdicAl STUDENTS' CONSCIOUSNESS OF HUMANITY AND MEDICAL ETHICS AND PRACTICES}

The clinical skills competition is a platform to show our individual skills and collective elegant demeanour which can form the charming symbol of "skilful craftsman". As we all know, many hands make light work, so the power of one person alone makes nothing. The clinical skills competition requires students to attend as a team with four persons. In this way, individual specialized knowledge and skills can be tested in the competition. As every student has his strong points and weak points on the personal quality and professional skills, the clinical skills competition builds a complementary platform for college students, and constructs a shared-resources space. In the competition, the communication skills of college students can be fostered to enhance a sense of community. In order to achieve better results, a large number of competitors take the initiative to train \& learn their skills and consult with clinical teachers in the skills training room of the hospital by using their spare time apart from learning and internship. Students grow to maturity in the process of competition and they are able to consider things more comprehensively and thoughtfully. Besides, they also gain more mature clinical thinking. To become a good doctor, first one must be noble in medical ethics and extremely responsible for the patient and society; and then he must have superb medical skills to be able to provide a high level of medical services. Both of these two aspects are indispensable [8]. Even students are practicing or operating on the mould, they are required to treat moulds like real patients with attention to informing, communicating, the hurt-loving concept and the protection medical treatment. Thus, the cultivation of students' medical ethics and practices can be further deepened in the process of clinical practices [9], [10].

\section{CONCLUSION}

All in all, the clinical skills competition breaks up the learning mode that medical students are only restricted to books, and enables students to get a profound exercise opportunity in clinical operation skills and clinical thinking abilities. Not only the launching of clinical skills competition provides a platform for students to show their skills and styles and focuses on presenting their clinical thinking abilities, clinical skills and humanistic spirits, so as to create a favourable atmosphere for promoting the constant increase in medical students' clinical skills. But also its launching supervises and urges the clinical teaching to be carried out orderly and efficiently. The clinical skills competition becomes an important platform and experience of medical students' growth and success, so the innovative ability of college students can be improved in the competition. On one hand, the launching of the clinical skills competition effectively promotes and stimulates student' $s$ innovative awareness and abilities in the skills competition, and it comprehensively enhances the clinical practical abilities of medical students. And on the other hand, it has great significance in encouraging students to continuously try their best to enhance their operational skills, thinking abilities and abilities to create, and helps them maintain a kind and caring heart in the future learning process and when they take up a job as a doctor.

\section{REFERENCES}

[1] S. B. Issenberg, W. C. McGaghie, E. R. Petrusa, D. Lee Gordon, and R. J. Scalese, "Features and uses of high-fidelity medical simulations that lead to effective learning: a BEME systematic review," Med Teach, vol. 27, no. 1, pp. 10-28, 2005.

[2] B. Lu, H. Hu, and G. Huang, "From clinical skills competition for medical students to find out inadequacies of current Medical Education," China Higher Medical Education, vol. 9, pp. 4-5, 2012.

[3] C. Du Boulay and C. Medway, "The clinical skills resource: a review of current practice," Med Educ, vol. 33, no. 3, pp. 185-191, 1999. 
[4] Y. Deng, J. Zhang, C. Liu, L. Jia, R. Zhang, and T. Shu, "The clinical skills resource: a review of current practice," Medicine Teaching in University, vol. 1, no. 1, pp. 45-48, 2011.

[5] W. Wu and Z. Yin, "Comparison of Medical Clinical Skill Examination," China Journal of Modern Medicine, vol. 13, no. 14, pp. $151-152,2003$.

[6] S. K. Jasani and N. S. Saks, "Utilizing visual art to enhance the clinical observation skills of medical students," Med Teach, vol. 3 , 2003.

[7] O. Doody and M. Condon, "Using a simulated environment to support students learning clinical skills," Nurse Educ Pract, vol. 1471-5953, no. 13, pp. 00069-3, 2003.

[8] A. M. González, "The assessment of clinical skills as a problem," Rev Esp Anestesiol Reanim, vol. 0034-9356, no. 13, pp. 00047-9, 2013.

[9] R. Cant, L. McKenna, and S, Cooper, "Assessing preregistration nursing students' clinical competence: A systematic review of objective measures," Int J Nurs Pract, vol. 19, no. 2, pp. 163-176, 2013

[10] M. Ruesseler, A. Schill, T. Stibane, A. Damanakis, I. Schleicher, S. Menzler, A. Braunbeck, and F. Walcher, "'Practical Clinical Competence"-A Joint Programme to Improve Training in Surgery Assessing preregistration nursing students' clinical competence: A systematic review of objective measures," Zentralbl Chir, vol. 10, 2013.

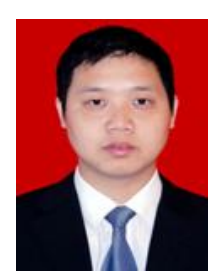

Jiang Linqiang was born in $\mathrm{Yi}$ Bin of Sichuan province; Basic Medical School of Luzhou Medical College; counselor; bachelor, engage in research of college students' ideological and political education.

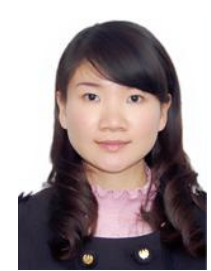

Fang Dan was born in Le Shan of Sichuan province; Basic Medical School of Luzhou Medical College; counselor; bachelor, engage in research of college students' ideological and political education.

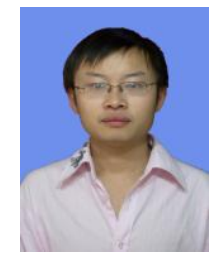

Luo Mao was born in Le Shan of Sichuan province; Basic Medical School of Luzhou Medical College; Assistant Research Fellow; bachelor, engage in research of college students' ideological and political education. 